\title{
Embalagens Termoformadas e Termoprocessáveis para Produtos Cárneos Processados
}

\author{
Léa M. Oliveira, Claire I. G. L. Sarantópoulos, Débora G. Cunha, Aline B. Lemos \\ Centro de Tecnologia de Embalagem, CETEA, SP
}

\begin{abstract}
Resumo: Carnes processadas refrigeradas são produtos de alto valor agregado, tradicionalmente acondicionados a vácuo em embalagens plásticas, que minimizam o contato do produto com o oxigênio do ar e, consequentemente, prolongam sua vida útil. Neste trabalho mapearam-se os materiais utilizados no mercado nacional para embalagens termoformadas de lingüiças, salsichas e frios fatiados e para embalagens tipo cook in de presuntos e apresuntados. Basicamente são utilizadas estruturas coextrusadas ou uma combinação de coextrusão com laminação (tampas). Poliamidas, EVOH e PET-PVDC são os materiais utilizados para conferir às embalagens barreira ao oxigênio. $\mathrm{A} \mathrm{TPO}_{2}$ dos filmes fundo para termoformação variou entre $5 \mathrm{e}$ $30 \mathrm{~cm}^{3}(\mathrm{CNTP}) / \mathrm{m}^{2} /$ dia, com valores mais baixos para os frios fatiados. A $\mathrm{TPO}_{2}$ das tampas foi da ordem de $10 \mathrm{~cm}^{3}(\mathrm{CNTP}) / \mathrm{m}^{2} /$ dia, todos a $23{ }^{\circ} \mathrm{C}$ e a úmido. A resistência à perfuração ficou em torno de $25 \mathrm{~N}$ (tampa) e $35 \mathrm{~N}$ (fundo linguiças/salsichas). Nos filmes fundo para frios fatiados houve grande variação na resistência à perfuração, em decorrência da ampla gama de espessuras disponíveis. Embalagens de mercado foram avaliadas quanto a integridade das selagens e distribuição de espessura do filme termoformado. Não foram detectados problemas de fechamento. A redução na espessura total do filme fundo, no canto de bandejas (região crítica) para salsichas e lingüiças, que têm maior profundidade de termoformação, variou entre 42 e $65 \%$, o que leva a uma significativa perda de barreira a gases da estrutura e justifica o emprego de $\mathrm{EVOH}$, um polímero de alta barreira a gases, a fim de não comprometer a vida útil do produto.
\end{abstract}

Palavras-chave: Embalagem plástica flexível, permeabilidade ao oxigênio, propriedades mecânicas, resistência à perfuração, embalagem de carnes.

\section{Thermoformed and Thermoprocessable Plastic Packages for Processed Meat}

Abstract: Refrigerated processed meats are high added-value products traditionally vacuum-packed in plastic packages to minimize contact of the product with oxygen and, consequently, prolong their shelf life. This study aimed at elaborating a comprehensive and detailed overview of the packaging materials used on the Brazilian market to manufacture thermoformed packages for sausages, hot dogs and sliced processed meat, in addition to cook in-type packages for hams and restructured ham products. Basically, the materials most used are coextruded films or a combination of coextruded and laminated (top film) structures. Polyamides, EVOH and PET-PVDC are used to provide an oxygen barrier. The oxygen transmission rate $\left(\mathrm{O}_{2} \mathrm{TR}\right)$ of bottom films for thermoformed packages varied between 5 and $30 \mathrm{~cm}^{3}(\mathrm{STP}) / \mathrm{m}^{2} /$ day, with lower values for the films used in the package of sliced processed meat. The $\mathrm{O}_{2}$ TR of top films were of the order of $10 \mathrm{~cm}^{3}(\mathrm{STP}) / \mathrm{m}^{2} / \mathrm{day}$, determined at $23{ }^{\circ} \mathrm{C}$ under wet conditions. Perforation resistance was about $25 \mathrm{~N}$ (top films) and $35 \mathrm{~N}$ (bottom films - sausages/ hot dogs). The bottom films for sliced processed meat varied considerably in terms of puncture resistance due to the wide range of thickness available. A series of packages currently in use on the Brazilian market were evaluated for seal integrity and thickness distribution of the thermoformed film. No sealing problems were detected. The reduction of total film thickness at the corner of flexible trays (critical area) for sausages and hot dogs, whose depth is larger than for sliced processed meat packages, varied between 42 and $65 \%$. The reduced thickness at the corners significantly affects the gas barrier properties of the package and justifies the use of EVOH which does not cause the shelf life to decrease.

Keywords: Flexible plastic packaging, oxygen permeability, mechanical properties, puncture resistance, meat package.

\section{Introdução}

Carnes e aves frescas e processadas são produtos com alto valor agregado, que requerem sistemas de embalagem, distribuição e estocagem capazes de garantir que o produto chegue ao consumidor final sem significativa perda de qualidade. Nestes produtos a perda de qualidade ocorre, principalmente, devido ao crescimento microbiano, à descoloração, à rancificação e à desidratação superficial, sendo possível o prolongamento da vida útil pela proteção adequada contra fatores do meio ambiente, como oxigênio, luz, umidade e contaminação microbiológica. Neste contexto a embalagem, a qualidade inicial do produto e a temperatura de estocagem/comercialização assumem grande

Autor para correspondência: Aline B. Lemos, Centro de Tecnologia de Embalagem - CETEA, Av. Brasil 2880, Cx. Postal 139, CEP: 13073-001, Campinas, SP. E-mail: aline@ital.sp.gov.br 
importância na manutenção da qualidade de carnes, aves e produtos derivados por longos períodos ${ }^{[1]}$.

A embalagem influencia a qualidade e a durabilidade de carnes e aves frescas e processadas, pois altera o ambiente ao redor do produto, criando condições que retardam as reações de deterioração. A embalagem previne a evaporação da umidade do produto, evitando perdas de peso e alterações de aparência, textura e aroma. Contudo, a maior alteração no ambiente que circunda o produto, provocada pela embalagem, é quanto à composição gasosa. Esta atmosfera irá determinar a cor do produto, o tipo e a extensão da deterioração microbiológica e a taxa de oxidação dos seus componentes.

$\mathrm{O}$ acondicionamento a vácuo, muito utilizado para carnes processadas, prolonga a vida útil do produto, permitindo o aumento do raio de distribuição do mesmo. Quando um produto é embalado a vácuo em uma embalagem barreira a gases, altera-se radicalmente a atmosfera gasosa ao seu redor. A pequena quantidade de oxigênio remanescente no interior da embalagem é consumida pela atividade metabólica da carne e das bactérias, criando-se, assim, um microssistema anaeróbio/ microaeróbio dentro da embalagem, que, auxiliado pelo efeito inibitório do $\mathrm{CO}_{2}$ liberado na respiração de microrganismos, retarda o crescimento de bactérias deterioradoras, como as Pseudomonas, permitindo a predominância de bactérias do ácido láctico, que têm menor potencial de deterioração e crescimento limitado a baixas temperaturas. O resultado é uma vida-de-prateleira mais longa ${ }^{[2]}$.

Nas embalagens a vácuo, a taxa de permeabilidade ao oxigênio do material influi diretamente na vida-de-prateleira do produto, pois a entrada de pequena quantidade de oxigênio na embalagem gera uma baixa pressão parcial deste gás, suficiente para a oxidação do pigmento de carnes frescas e curadas. Por outro lado, a presença de lacres de identificação da marca, grampos e outras regiões pontiagudas, exige embalagens com alta resistência à perfuração. A perfuração do filme provocará perda de vácuo e conseqüente falha do sistema de conservação. Boas características de termossoldagem também são fundamentais para manter a integridade da embalagem e garantir a vida útil do produto.

São utilizados para embalagens a vácuo filmes encolhíveis ou não, termoformáveis ou não. Sua composição, espessura e conseqüentes propriedades são função da aplicação e vida útil desejada.

Neste trabalho foram mapeadas as características de filmes barreira a gases utilizados em embalagens a vácuo termoformáveis e/ou termoprocessáveis, estas últimas utilizadas para o acondicionamento de produtos cárneos termoprocessados dentro da própria embalagem. Avaliou-se também a integridade e a distribuição de espessura de embalagens termoformadas disponíveis no mercado.

\section{Experimental}

\section{Materiais}

Avaliou-se filmes/embalagens multicamadas termoprocessáveis e termoformáveis utilizados para o acondiciona- mento a vácuo de produtos cárneos processados. Vinte e duas embalagens na forma de filme plano, sem uso, coletadas entre fabricantes nacionais, foram caracterizadas quanto à estrutura, resistência mecânica e barreira ao oxigênio. Dezesseis embalagens de mercado foram avaliadas quanto à integridade do fechamento e quanto à distribuição de espessura.

\section{Caracterização das embalagens}

As embalagens foram caracterizadas quanto à composição polimérica, espessura total e de cada camada.

A identificação dos polímeros utilizados nos filmes multicamadas foi feita por espectroscopia no infravermelho, em equipamento Perkin Elmer, com transformada de Fourier, modelo FTIR 1650. Utilizou-se as técnicas de leitura direta e reflexão interna múltipla (janela de KRS 5 com $45^{\circ}$ ). Solventes orgânicos e ácidos, à temperatura ambiente e ou aquecidos, foram utilizados para separação das camadas das estruturas ${ }^{[3]}$.

As espessuras parcial (de cada camada) e total dos filmes planos foram determinadas com micrômetro de ponta plana, com resolução de $1 \mu \mathrm{m}$. Foram feitas cerca de 25 determinações por amostra. Os ensaios foram conduzidos em ambiente a cerca de $23^{\circ} \mathrm{C}$ e $50 \%$ de umidade relativa, após condicionamento das amostras por 24 horas neste mesmo ambiente ${ }^{[3]}$

\section{Avaliação de resistência mecânica}

A resistência mecânica das embalagens foi avaliada por meio da determinação da resistência à perfuração, segundo procedimento descrito na norma ASTM F 1306-90[4], em máquina universal de ensaios Instron, modelo 5500R, operando com célula de carga de $100 \mathrm{~N}$. A velocidade de perfuração, realizada com uma ponteira metálica de ponta esférica, com diâmetro de cerca de $3,2 \mathrm{~mm}$, foi de $25 \mathrm{~mm} / \mathrm{min}$. A perfuração foi realizada da camada interna para a externa. O ensaio foi realizado em ambiente a cerca de $23{ }^{\circ} \mathrm{C}$ e $50 \%$ de umidade relativa, após condicionamento da amostra por 24 horas neste mesmo ambiente.

\section{Barreira ao oxigênio}

A barreira ao oxigênio foi quantificada por meio da medida da taxa de permeabilidade ao oxigênio $\left(\mathrm{TPO}_{2}\right)$, determinada por método coulométrico, segundo procedimento descrito na norma ASTM F 1927-98[5], em equipamento OXTRAN, modelo 2/20 da MOCON, operando com oxigênio puro como gás permeante à temperatura de $23^{\circ} \mathrm{C}$ e a úmido. $\mathrm{O}$ condicionamento dos corpos-de-prova foi feito durante 2 dias, a $23{ }^{\circ} \mathrm{C}$ e a úmido (ambiente saturado com água). Os resultados obtidos foram corrigidos para $1 \mathrm{~atm}$ de gradiente de pressão parcial de oxigênio.

\section{Integridade}

A integridade do fechamento foi avaliada com o ensaio de penetração de solução colorida, que consistiu na colocação de pequena quantidade de uma solução colorida de $0,5 \%$ de rodamina em isopropanol na região interna da termossoldagem. Com baixa tensão superficial, esta solução é capaz de penetrar em microcanais com até $20 \mu \mathrm{m}$ de diâmetro, 


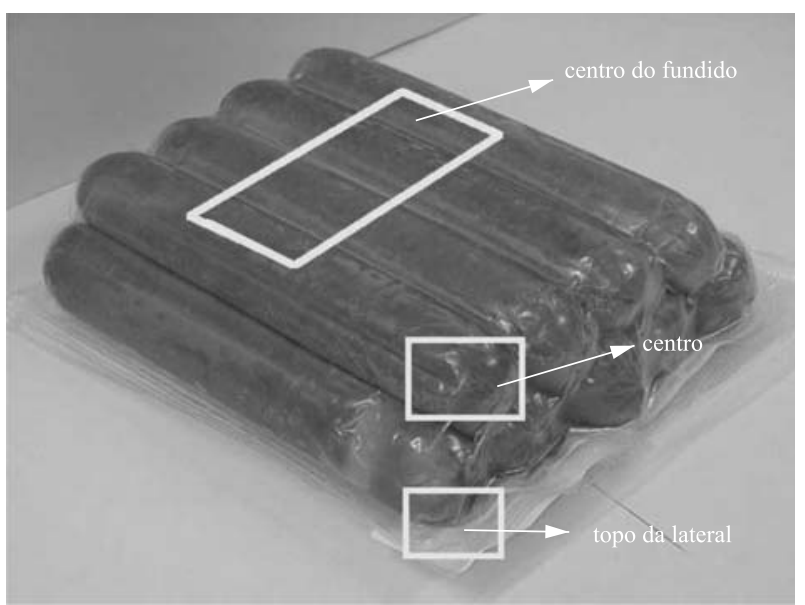

Figura 1. Indicação das posições de determinação de espessura nas embalagens de mercado.

evidenciando falhas no sistema de fechamento ${ }^{[3]}$. Três unidades de cada amostra foram avaliadas

\section{Distribuição de espessura}

As espessuras parciais e totais das embalagens de mercado foram determinadas em microscópio ótico acoplado a um sistema de análise de imagem, operando com um aumento de 200 vezes. Nas amostras de mercado de embalagens de salsicha e lingüiça, a espessura foi determinada em três regiões da bandeja termoformada: canto, centro do fundo e topo da lateral (Figura 1). Nas amostras de frios fatiados, devido à menor profundidade de termoformação, os corpos-de-prova foram retirados apenas dos cantos e do centro do fundo. Os corposde-prova foram retirados de duas embalagens por amostra, o que resultou em um total de 8 espécimes do canto e do topo da lateral e 6 do centro do fundo. Em cada corpo-de-prova foram feitas 5 medidas, totalizando 40 determinações no canto e no topo da lateral e 30 no centro do fundo.

\section{Resultados e Discussão}

\section{Embalagens sem uso}

Na Tabela 1 são apresentados os resultados obtidos para as embalagens termoprocessáveis, sem uso. Sete filmes foram analisados e constatou-se que quatro deles, de um mesmo fabricante, apresentavam a mesma estrutura (amostra 1). Considerando então as 4 amostras diferentes analisadas, duas apresentaram apenas PA (poliamida) como material barreira e outras duas EVOH (copolímero de etileno e álcool vinílico) na estrutura, o que aumenta a barreira ao oxigênio do material, conferindo maior proteção ao produto contra a oxidação. Os filmes com PA apresentaram $\mathrm{TPO}_{2}$ entre 32 e $72 \mathrm{~cm}^{3}(\mathrm{CNTP}) / \mathrm{m}^{2} /$ dia e os filmes com EVOH apresentaram $\mathrm{TPO}_{2}$ menor que 5 $\mathrm{cm}^{3}(\mathrm{CNTP}) / \mathrm{m}^{2} /$ dia a $23^{\circ} \mathrm{C}$, o que justifica sua utilização na embalagem de produtos cárneos curados cozidos, como presunto, apresuntado e similares, cuja coloração é muito sensível à oxidação e conseqüente perda da desejável coloração rósea. A resistência à perfuração variou, em média, entre $21 \mathrm{e}$ $73 \mathrm{~N}$ e a energia para tanto entre 0,16 e $0,32 \mathrm{~J}$, valores da mesma ordem de grandeza dos encontrados para tripas plásti$\mathrm{cas}^{[6]}$. Na amostra 4 , as duas camadas de poliamida, com espessura total da ordem de $47 \mu \mathrm{m}$, resultaram em uma resistência à perfuração significativamente superior às das demais amostras. Vale ressaltar as boas propriedades de barreira e resistência mecânica da amostra 3 , a despeito de sua reduzida espessura. Verifica-se uma tendência de redução de material nos filmes sem perda das propriedades desejáveis.

Na Tabela 2 são apresentados os dados referentes a filmes planos utilizados para acondicionamento a vácuo de salsichas e lingüiças, em porções de até $500 \mathrm{~g}$, em bandejas flexíveis termoformadas, as quais são compostas por tampa e fundo termoformado.

Verificou-se uma tendência de uso de tampas pigmentadas de branco, um recurso para barrar a luz ultravioleta e visível, catalisadoras da reação de oxidação de pigmentos e gordura, que resulta na degradação da cor e no desenvolvimento de odor e sabor indesejáveis no produto. Observou-se também que todas as tampas têm como camada externa o filme de poliéster, que alia propriedades mecânicas, como resistência à abrasão e à perfuração, com propriedades óticas, como brilho e transparência, que realçam a impressão. A qualidade visual deste tipo de embalagem é um requisito importante para a venda no varejo, onde produtos concorrentes encontram-se lado a lado nas gôndolas e devem conquistar o consumidor em segundos.

Tabela 1. Características de embalagens termoprocessáveis, na forma de filme plano.

\begin{tabular}{|c|c|c|c|c|c|c|c|}
\hline \multirow[b]{2}{*}{ Amostra } & \multirow[b]{2}{*}{ Estrutura } & \multicolumn{2}{|c|}{$\operatorname{Espessura}^{a}(\mu \mathrm{m})$} & \multirow{2}{*}{$\begin{array}{c}\mathrm{TPO}_{2}^{\mathrm{b}}\left(\mathrm{cm}^{3}(\mathrm{CNTP}) /\right. \\
\left(\mathrm{m}^{2} . \operatorname{dia}\right) 1 \mathrm{~atm}, 23^{\circ} \mathrm{C} / \\
75-80 \% \mathrm{UR}\end{array}$} & \multicolumn{3}{|c|}{ Perfuraçãa ${ }^{C}$} \\
\hline & & Total & Parcial & & $\begin{array}{c}\text { Resistência } \\
\text { (N) }\end{array}$ & $\begin{array}{c}\text { Energia } \\
(\mathbf{J})\end{array}$ & $\begin{array}{c}\text { Deformação } \\
(\mathrm{mm})\end{array}$ \\
\hline 1 & $\mathrm{imp} / \mathrm{EVAbco} / \mathrm{PE} / \mathrm{EVOH} / \mathrm{PA}$ & $69^{d}$ & $19 / 21 / 12 / 6$ & 4,02 & 50,9 & 0,23 & 8,9 \\
\hline 2 & $\mathrm{imp} / \mathrm{PAbco} / \mathrm{EMAA}$ & 71 & $31 / 41$ & 72,2 & 20,8 & 0,16 & 13 \\
\hline 3 & EVA/EVOH/PP & 36 & $11 / 8 / 17$ & 4,97 & 39,4 & 0,18 & 8,2 \\
\hline 4 & $\mathrm{PA} / \mathrm{PE} / \mathrm{PA}$ & 52 & $27 / 7 / 20$ & 32,3 & 73,1 & 0,32 & 8,1 \\
\hline
\end{tabular}

Valores médios referentes a $25\left(^{(\mathrm{a}}\right), 2\left({ }^{\mathrm{b}}\right), 10\left(^{\mathrm{c}}\right)$ e $15\left(^{\mathrm{d}}\right)$ determinações

imp: impressão bco: pigmentado de branco

$\mathrm{TPO}_{2}$ : taxa de permeabilidade ao oxigênio

Espessura parcial: espessura de cada camada 
Tabela 2. Características de filmes planos, tampa e fundo, utilizados para salsichas e lingüiças acondicionadas em embalagens termoformadas.

\begin{tabular}{|c|c|c|c|c|c|c|c|}
\hline \multirow[b]{2}{*}{ Amostra } & \multirow[b]{2}{*}{ Estrutura } & \multicolumn{2}{|c|}{ Espessura $^{a}(\mu \mathrm{m})$} & \multicolumn{3}{|c|}{ Perfuraçãa $^{\text {b }}$} & \multirow{2}{*}{$\begin{array}{c}\mathrm{TPO}_{2}{ }^{\mathrm{c}}\left(\mathrm{cm}^{3}(\mathrm{CNTP}) /\right. \\
\left(\mathrm{m}^{2} . \operatorname{dia}\right) 1 \mathrm{~atm}, 23{ }^{\circ} \mathrm{C} / \\
75-80 \% \mathrm{UR}\end{array}$} \\
\hline & & Total & Parcial & $\begin{array}{c}\text { Resistência } \\
\text { (N) }\end{array}$ & $\begin{array}{c}\text { Energia } \\
(\mathbf{m J})\end{array}$ & $\begin{array}{l}\text { Deformação } \\
(\mathbf{m m})\end{array}$ & \\
\hline Tampa 1 & PET-PVDC/imp/PEbco & $84^{\mathrm{d}}$ & $14 / 69$ & 23,1 & 64 & 5,3 & 11,7 \\
\hline Tampa 2 & $\mathrm{PET} / \mathrm{imp} / \mathrm{PEbco} / \mathrm{PA} / \mathrm{PE}$ & 81 & $13 / 16 / 24 / 28$ & 26,2 & 67 & 4,8 & 24,3 \\
\hline Tampa 3 & PET/imp/PEbco/EVOH/PEbco & $81^{\mathrm{d}}$ & $12 / 38 / 8,9 / 20$ & 24,4 & 61 & 4,7 & 2,40 \\
\hline Tampa 4 & $\mathrm{PET} / \mathrm{PE} / \mathrm{EVOH} / \mathrm{PE}$ & 84 & $14 / 19 / 12 / 39$ & 22,6 & 63 & 4,7 & 3,52 \\
\hline Fundo 1 & $\mathrm{PA} / \mathrm{EVA} / \mathrm{PA} / \mathrm{EVA}$ & 102 & $15 / 6,7 / 35 / 45$ & 36,1 & 256 & 12,3 & 30,2 \\
\hline Fundo 2 & $\mathrm{PE} / \mathrm{PA} / \mathrm{PE} / \mathrm{PA} / \mathrm{PE}$ & 118 & $35 / 36 / 6 / 16 / 26$ & 32,7 & 252 & 13,2 & 25,8 \\
\hline
\end{tabular}

Valores referentes a $15\left(^{(a)}, 10\left(^{b}\right), 2\left(^{c}\right)\right.$ e $25\left(^{d}\right)$ determinações

imp: impressão bco: pigmentado de branco

$\mathrm{TPO}_{2}$ : taxa de permeabilidade ao oxigênio

Espessura parcial: espessura de cada camada

Todos os quatro filmes tampa analisados têm como camada selante o polietileno, material que também confere à estrutura barreira ao vapor d'água. A barreira ao oxigênio foi proporcionada pelo revestimento de PVDC (copolímero de cloreto de vinila e cloreto de vinilideno) no filme de PET (politereftalato de etileno) (amostra1), PA (amostra 2) ou EVOH (amostras 3 e 4). O emprego do EVOH melhora consideravelmente as propriedades de barreira ao oxigênio do filme, em relação à estrutura com PET-PVDC e àquela com poliamida.

O fundo das embalagens termoformadas de salsicha e lingüiça são basicamente compostos por materiais coextrusados, com espessura da ordem de $100 \mu \mathrm{m}$, sendo os polímeros mais usuais as poliamidas e o polietileno. A poliamida, além de conferir à estrutura características de barreira ao oxigênio e resistência mecânica, permite a termoformação. O polietileno permite o fechamento por calor e confere barreira ao vapor d'água suficiente para garantir a qualidade sensorial do produto.

A permeabilidade ao oxigênio dos filmes de fundo variou na faixa de 25 a $30 \mathrm{~cm}^{3}(\mathrm{CNTP}) / \mathrm{m}^{2} /$ dia a $23{ }^{\circ} \mathrm{C}$ e a úmido (Tabela 2), enquanto nos filmes de tampa variou entre $2,40 \mathrm{e}$ $24,3 \mathrm{~cm}^{3}(\mathrm{CNTP}) / \mathrm{m}^{2} /$ dia a $23{ }^{\circ} \mathrm{C}$ a úmido, predominando filmes com permeabilidade inferior à $10 \mathrm{~cm}^{3}(\mathrm{CNTP}) / \mathrm{m}^{2} /$ dia a $23{ }^{\circ} \mathrm{C}$. Isto demonstra que muita vezes é utilizado pelo mercado, em embalagens termoformadas para salsicha e lingüiça, um filme tampa com taxa de permeabilidade ao oxigênio muito inferior à do filme de fundo, o que não se justifica em termos de proteção do produto, visto que o filme plano do fundo é inicialmente mais permeável e ainda será termoformado, ficando mais fino e, portanto, mais permeável. Por outro lado, a permeabilidade do filme de tampa é menor e não irá se alterar quando aplicado à embalagem. Outro fator que não justifica a menor permeabilidade do filme de tampa é a maior área do fundo da embalagem comparativamente à área da tampa, especialmente quando se tem termoformação profunda. A maior área exposta à permeação de gases associada à maior $\mathrm{TPO}_{2}$ fará com que o fundo afete significativamente a entrada total de oxigênio pela embalagem.
As variações na estrutura das tampas utilizadas para salsichas e lingüiças, cujas espessuras totais variaram em torno de 80 a $85 \mu \mathrm{m}$, não resultaram em alterações significativas na resistência à perfuração, em torno de $25 \mathrm{~N}$, provavelmente pela significativa contribuição do filme PET para esta propriedade. Nos filmes fundo, a resistência à perfuração foi da ordem de $35 \mathrm{~N}$ e a energia para perfuração foi de $0,25 \mathrm{~J}$. Estes valores devem ser significativamente reduzidos após a termoformação, especialmente nos cantos da embalagem, devido à redução na espessura do material.

Os resultados obtidos para os filmes planos utilizados no acondicionamento de frios fatiados em embalagens flexíveis termoformadas são apresentados na Tabela 3. Também neste caso foram detectados os mesmos filmes tampa e fundo sendo utilizados para diferentes produtos ou por diferentes frigoríficos.

No segmento de frios fatiados foram encontradas as estruturas mais sofisticadas e, provavelmente, as de maior custo, uma vez que além dos polímeros convencionais apresentam também o EVOH e/ou a metalização. Esta composição tem influência direta nas propriedades de barreira ao oxigênio do material, conferindo às estruturas $\mathrm{TPO}_{2}$ em geral abaixo de $5 \mathrm{~cm}^{3}(\mathrm{CNTP}) / \mathrm{m}^{2} /$ dia a $23^{\circ} \mathrm{C}$, a úmido. As pequenas porções (maior relação área embalagem /peso produto) e a grande área exposta de produto devido ao fatiamento tornam os mesmos mais susceptíveis ao contato com o oxigênio, daí a justificativa pela procura por materiais de alta barreira.

As embalagens de frios fatiados, a exemplo das de salsichas e lingüiças, devem causar impacto no consumidor, destacando-se nas gôndolas e ao mesmo tempo apresentar resistência mecânica. Tendo em vista estas propriedades, o PET, algumas vezes metalizado, é utilizado como camada externa nos filmes tampa. EVOH ou PA aparecem como barreira ao oxigênio, sendo que a poliamida também auxilia nas propriedades mecânicas. Como nos filmes de tampa para salsicha e lingüiça, a camada interna de PE (polietileno) ou EVA (copolímero de etileno e acetato de vinila) permite o 
Tabela 3. Características de filmes planos de tampa e fundo utilizados para frios fatiados acondicionados em embalagens termoformadas.

\begin{tabular}{|c|c|c|c|c|c|c|c|}
\hline \multirow[b]{2}{*}{ Amostra } & \multirow[b]{2}{*}{ Estrutura } & \multicolumn{2}{|c|}{ Espessura $^{\mathrm{a}}(\mu \mathrm{m})$} & \multicolumn{3}{|c|}{ Perfuração $^{b}$} & \multirow{2}{*}{$\begin{array}{c}\mathrm{TPO}_{2}{ }^{\mathrm{c}}\left(\mathrm{cm}^{3}(\mathrm{CNTP}) /\right. \\
\left(\mathrm{m}^{2} . \operatorname{dia}\right) 1 \mathrm{~atm}, 23{ }^{\circ} \mathrm{C} / \\
75-80 \% \mathrm{UR}\end{array}$} \\
\hline & & Total & Parcial & $\begin{array}{c}\text { Resistência } \\
(\mathbf{N})\end{array}$ & $\begin{array}{c}\text { Energia } \\
(\mathrm{mJ})\end{array}$ & $\begin{array}{c}\text { Deformação } \\
(\mathbf{m m})\end{array}$ & \\
\hline Tampa 1 & $\mathrm{PET} / \mathrm{imp} / \mathrm{met} / \mathrm{PE} / \mathrm{PA} / \mathrm{PE}$ & 92 & $14 / 20 / 7 / 51$ & 16,0 & 67 & 4,8 & 5,56 \\
\hline Tampa 2 & PET/imp/met/PE/EVOH/EVA & 98 & $14 / 46 / 8 / 28$ & 26,6 & 71 & 5,1 & 0,82 \\
\hline Tampa 3 & PET/imp/met/EVOH/PE & 75 & $23 / 12 / 36$ & 12,1 & 70 & 5,0 & 0,35 \\
\hline Tampa 4 & PET/imp/PE/EVOH/PE & 92 & $14 / 29 / 10 / 40$ & 26,3 & 63 & 4,6 & 5,75 \\
\hline Tampa 5 & PET/imp/PE/EVOH/EVA & 235 & $14 / 53 / 10 / 163$ & 74,6 & 372 & 7,9 & 1,77 \\
\hline Fundo 1 & $\mathrm{PA} / \mathrm{PE} / \mathrm{PA} / \mathrm{EVOH} / \mathrm{PA} / \mathrm{PE}$ & $128^{\mathrm{d}}$ & $\begin{array}{c}14 / 64 / 15 / \\
9 / 25 / 21\end{array}$ & 26,3 & 165 & 10,6 & 1,78 \\
\hline Fundo 2 & $\mathrm{PA} / \mathrm{PE} / \mathrm{EVOH} / \mathrm{PE}$ & 135 & $22 / 13 / 18 / 84$ & 18,6 & 93 & 7,5 & 1,35 \\
\hline Fundo 3 & $\mathrm{PET} / \mathrm{met} / \mathrm{PA} / \mathrm{PE} / \mathrm{EVOH} / \mathrm{PE}$ & 83 & $8 / 18 / 7 / 9 / 39$ & 26,1 & 67 & 4,9 & $<0,4$ \\
\hline Fundo 4 & $\mathrm{PE} / \mathrm{EVOH} / \mathrm{PE}$ & 67 & $31 / 12 / 22$ & 30,0 & 247 & 13,6 & 21,4 \\
\hline
\end{tabular}

Valores referentes a $15\left(^{\mathrm{a}}\right), 10\left({ }^{\mathrm{b}}\right), 2\left({ }^{\mathrm{c}}\right)$ e $25\left(^{\mathrm{d}}\right)$ determinações

imp: impressão met: metalização

$\mathrm{TPO}_{2}$ : taxa de permeabilidade ao oxigênio

Espessura parcial: espessura de cada camada

fechamento da embalagem por meio da aplicação de calor e confere propriedade de barreira ao vapor d'água à estrutura.

$\mathrm{O}$ fundo das embalagens de frios fatiados diferencia-se dos utilizados para salsicha e lingüiça pela presença, na maioria deles, de $\mathrm{EVOH}$, para aumentar a barreira ao oxigênio e, em muitas estruturas, pela ausência de PA, tendo em vista que a termoformação destas embalagens é menos profunda que nas de salsicha.

A espessura total das tampas variou entre 92 e $235 \mu \mathrm{m}$, com a resistência à perfuração e a energia necessária para tanto variando entre 12 e $75 \mathrm{~N}$ e 63 e $372 \mathrm{~mJ}$, respectivamente. $\mathrm{O}$ amplo intervalo de variação nas propriedades de perfuração é devido à variação na espessura do filme e dos materiais poliméricos.

A espessura total do fundo variou de 67 a $135 \mu \mathrm{m}$, enquanto a resistência à perfuração e a energia, entre cerca de 19 e $30 \mathrm{~N}$ e 67 e $247 \mathrm{~mJ}$. A maior espessura total de poliamida do Fundo 1, $54 \mu \mathrm{m}$, em relação à espessura das poliamidas do Fundo 2, $22 \mu \mathrm{m}$, resultou em maior resistência à perfuração. Por sua vez, no Fundo 3, cerca de $18 \mu \mathrm{m}$ de PA associada a cerca de $8 \mu \mathrm{m}$ de PET resultaram em uma resistência à perfuração da mesma ordem de grandeza à detectada no Fundo 1. Ou seja, associando-se uma camada de PET a uma de PA, com uma espessura total destes materiais da ordem de $26 \mu \mathrm{m}$, é possível atingir uma resistência à perfuração similar à obtida apenas com poliamidas $(54 \mu \mathrm{m})$, ao mesmo tempo que se reduz a espessura total. Por outro lado, o material é perfurado com uma energia e deformação consideravelmente inferiores.

Resultado interessante foi obtido para o Fundo 4, uma estrutura de menor espessura, com transparência superior a das demais amostras, que não tem na sua estrutura a poliamida, o material mais associado à resistência mecânica em embalagens barreira a gases para produtos cárneos. Esta estrutura apresentou resistência à perfuração ligeiramente superior a dos outros fundos, mas que exige uma energia para perfurar muito superior, o que deve-se à elevada extensibilidade do filme, cuja deformação, no momento da perfuração, era de cerca de $14 \mathrm{~mm}$, contra 11 e $5 \mathrm{~mm}$ nos Fundos 1 e 3 respectivamente. Estes resultados foram obtidos, provavelmente, devido ao uso de polietilenos especiais, a exemplo dos lineares de octeno e hexeno e dos metalocênicos, desenvolvidos para conferir resistência mecânica e boas características de termossoldagem.

A exemplo dos fundos de salsicha e lingüiça, os valores de perfuração serão reduzidos com a termoformação, embora em menor grau, já que as embalagens são menos profundas, o que resulta em menor estiramento do material e, conseqüentemente, menor redução de espessura.

Considerando todas as amostras analisadas, os tipos de poliamida mais encontrados foram a PA 6 e o copolímero PA 6/66, o que coincide com dados de literatura, que citam que as poliamidas mais utilizadas no Brasil para embalagens são a PA 6 e a PA 6/66, esta última na proporção de 80:20. Estes polímeros têm uma boa processabilidade, o que facilita sua coextrusão com polímeros termicamente mais sensíveis como as poliolefinas ${ }^{[7,8]}$

\section{Amostras de mercado}

As 6 amostras de salsicha e de lingüiça e as 10 de frios fatiados adquiridas no mercado não apresentaram problemas de integridade na região de termossoldagem. Considerando que há grande preocupação com a barreira ao oxigênio do material de embalagem utilizado para estes produtos, frente aos problemas de oxidação aos quais são susceptíveis em diferentes graus, podemos afirmar que o investimento feito nos materiais de embalagem, em geral com média a alta barreira 
Tabela 4. Avaliação de embalagens termoformadas de mercado - salsichas e lingüiças.

\begin{tabular}{|c|c|c|c|c|c|c|c|}
\hline \multirow{3}{*}{ Amostra } & \multicolumn{7}{|c|}{ *Distribuição da espessura na embalagem termoformada $(\mu \mathrm{m})$} \\
\hline & \multirow{2}{*}{ Camada } & \multicolumn{2}{|c|}{ Canto $^{a}$} & \multicolumn{2}{|c|}{ Centro $^{b}$} & \multicolumn{2}{|c|}{ Topo da Lateral ${ }^{a}$} \\
\hline & & Média & IV & Média & IV & Média & IV \\
\hline \multirow{5}{*}{$\begin{array}{c}1 \\
\text { Salsicha } \\
\text { Hot Dog } \\
\text { marca } 1\end{array}$} & Total & 40 & $30-50$ & 85 & $72-95$ & 116 & $93-141$ \\
\hline & PA & 10 & $4-16$ & 23 & $17-28$ & 30 & $21-39$ \\
\hline & PE & 3 & $2-5$ & 8 & $5-13$ & 10 & $7-17$ \\
\hline & PA & 11 & $7-16$ & 20 & $10-24$ & 31 & $23-49$ \\
\hline & $\mathrm{PE}$ & 14 & $10-19$ & 33 & $23-45$ & 46 & $34-59$ \\
\hline \multirow{5}{*}{$\begin{array}{c}2 \\
\text { Salsicha } \\
\text { Hot Dog } \\
\text { marca } 4\end{array}$} & Total & 46 & $36-57$ & 102 & $85-120$ & 124 & $109-138$ \\
\hline & PA & 11 & $7-14$ & 21 & $16-27$ & 23 & $19-27$ \\
\hline & PE & 4 & $3-10$ & 7 & $4-12$ & 11 & $7-14$ \\
\hline & PA & 10 & $6-12$ & 21 & $16-26$ & 26 & $21-30$ \\
\hline & PE & 22 & $14-28$ & 53 & $41-61$ & 65 & $53-76$ \\
\hline \multirow{5}{*}{$\begin{array}{c}3 \\
\text { Salsicha } \\
\text { Hot Dog } \\
\text { marca } 5\end{array}$} & Total & 50 & $40-60$ & 78 & $71-90$ & 107 & $97-116$ \\
\hline & PA & 12 & $7-16$ & 17 & $13-22$ & 23 & $19-29$ \\
\hline & EVA & 7 & $4-13$ & 10 & $6-13$ & 11 & $8-15$ \\
\hline & PA & 9 & $5-17$ & 15 & $11-19$ & 19 & $16-22$ \\
\hline & EVA & 22 & $14-34$ & 38 & $33-43$ & 54 & $45-61$ \\
\hline \multirow{5}{*}{$\begin{array}{c}4 \\
\text { Lingüiça } \\
\text { Frango } \\
\text { marca } 6\end{array}$} & Total & 46 & $37-60$ & 94 & $70-115$ & 111 & $90-126$ \\
\hline & PA & 10 & $6-16$ & 21 & $13-29$ & 21 & $14-27$ \\
\hline & PE & 5 & $3-8$ & 10 & $7-13$ & 13 & $8-23$ \\
\hline & EVOH & 4 & $3-6$ & 9 & $5-12$ & 10 & $7-14$ \\
\hline & PE & 27 & $21-38$ & 55 & $39-65$ & 67 & $58-65$ \\
\hline \multirow{5}{*}{$\begin{array}{c}5 \\
\text { Lingüiça } \\
\text { Calabresa } \\
\text { marca } 7\end{array}$} & Total & 64 & $47-76$ & 84 & $66-107$ & 111 & $90-127$ \\
\hline & PA & 18 & $9-24$ & 25 & $20-33$ & 34 & $24-41$ \\
\hline & $\mathrm{PE}$ & 6 & $3-9$ & 7 & $4-14$ & 8 & $6-10$ \\
\hline & PA & 11 & $7-15$ & 14 & $10-22$ & 18 & $13-23$ \\
\hline & PE & 27 & $18-37$ & 37 & $30-50$ & 50 & $36-67$ \\
\hline \multirow{5}{*}{$\begin{array}{c}6 \\
\text { Lingüiça } \\
\text { Calabresa } \\
\text { marca } 6\end{array}$} & Total & 65 & $49-80$ & 90 & $77-116$ & 118 & $96-142$ \\
\hline & PA & 13 & $5-23$ & 18 & $101-32$ & 26 & $9-40$ \\
\hline & $\mathrm{PE}$ & 6 & $3-12$ & 7 & $5-10$ & 9 & $6-13$ \\
\hline & PA & 17 & $12-22$ & 24 & $19-30$ & 31 & $21-38$ \\
\hline & PE & 29 & $20-37$ & 40 & $27-51$ & 53 & $43-64$ \\
\hline
\end{tabular}

Valores referentes a $80\left(^{\mathrm{a}}\right)$ e $30\left(^{(b)}\right.$ determinações

IV: intervalo de variação

*: vide Figura 1 
Tabela 5. Avaliação de embalagens termoformadas de mercado - frios fatiados.

\begin{tabular}{|c|c|c|c|c|c|}
\hline \multirow{3}{*}{ Amostra } & \multirow{3}{*}{ Camada } & \multicolumn{4}{|c|}{ *Espessura fundo $(\mu \mathrm{m})$} \\
\hline & & \multicolumn{2}{|c|}{ Canto $^{\mathrm{a}}$} & \multicolumn{2}{|c|}{ Centro $^{b}$} \\
\hline & & Média & IV & Média & IV \\
\hline \multirow{5}{*}{$\begin{array}{c}1 \\
\text { Salame } \\
\text { italiano } \\
\text { marca } 1\end{array}$} & Total & 111 & $84-128$ & 107 & $98-117$ \\
\hline & $\mathrm{PA}$ & 16 & $10-23$ & 16 & $13-20$ \\
\hline & PE & 13 & $10-20$ & 12 & $9-16$ \\
\hline & $\mathrm{PA} / \mathrm{EVOH} / \mathrm{PA}$ & 11 & $8-17$ & 11 & $7-15$ \\
\hline & PE & 70 & $52-83$ & 68 & $61-78$ \\
\hline \multirow{5}{*}{$\begin{array}{c}2 \\
\text { Salame } \\
\text { italiano } \\
\text { marca } 2\end{array}$} & Total & 110 & $96-120$ & 117 & $110-125$ \\
\hline & PA $6 / 66$ & 10 & $16-26$ & 20 & $15-24$ \\
\hline & PE & 21 & $16-26$ & 16 & $11-20$ \\
\hline & $\mathrm{PA} / \mathrm{EVOH} / \mathrm{PA}$ & 15 & $11-20$ & 11 & $8-15$ \\
\hline & PE & 66 & $59-76$ & 68 & $63-76$ \\
\hline \multirow{5}{*}{$\begin{array}{c}3 \\
\text { Salame } \\
\text { italiano } \\
\text { marca } 3\end{array}$} & Total & 114 & $104-122$ & 120 & $113-127$ \\
\hline & PA & 13 & $14-15$ & 13 & $10-27$ \\
\hline & PE & 21 & $16-27$ & 26 & $22-30$ \\
\hline & $\mathrm{PA} / \mathrm{EVOH} / \mathrm{PA}$ & 11 & $8-14$ & 14 & $8-17$ \\
\hline & PE & 72 & $68-77$ & 72 & $68-77$ \\
\hline \multirow{5}{*}{$\begin{array}{c}4 \\
\text { Salame } \\
\text { italiano } \\
\text { marca } 4\end{array}$} & Total & 103 & $89-118$ & 117 & $103-132$ \\
\hline & PA & 20 & $14-25$ & 23 & $17-29$ \\
\hline & $\mathrm{PE}$ & 11 & $8-18$ & 11 & $9-14$ \\
\hline & $\mathrm{EVOH}$ & 10 & $7-15$ & 12 & $6-17$ \\
\hline & PE & 63 & $50-73$ & 73 & $57-88$ \\
\hline \multirow{6}{*}{$\begin{array}{c}5 \\
\text { Salame } \\
\text { italiano } \\
\text { marca } 5\end{array}$} & Total & 77 & $72-82$ & 80 & $74-88$ \\
\hline & PETmet & 12 & $9,0-16$ & 11 & $7,8-14$ \\
\hline & PA & 19 & $17-23$ & 19 & $17-21$ \\
\hline & PE & 4,8 & $3,0-7,0$ & 5,4 & $3,7-8,7$ \\
\hline & EVOH & 13 & $10-15$ & 12 & $8,5-16$ \\
\hline & PE & 29 & $24-33$ & 33 & $30-38$ \\
\hline \multirow{6}{*}{$\begin{array}{c}6 \\
\text { Lombo } \\
\text { canadense } \\
\text { marca } 9\end{array}$} & Total & 104 & $86-120$ & 115 & $100-126$ \\
\hline & BOPP & 22 & $17-27$ & 27 & $20-40$ \\
\hline & PA & 16 & $11-18$ & 16 & $10-18$ \\
\hline & EVOH & 12 & $10-17$ & 13 & $7-17$ \\
\hline & PA & 14 & $11-18$ & 16 & $13-23$ \\
\hline & PE & 39 & $26-50$ & 42 & $37-38$ \\
\hline \multirow{4}{*}{$\begin{array}{c}7 \\
\text { Lombo } \\
\text { defumado } \\
\text { marca } 5\end{array}$} & Total & 62 & $53-80$ & 70 & $62-78$ \\
\hline & PE & 27 & $23-37$ & 32 & $25-38$ \\
\hline & EVOH & 8 & $5-11$ & 8 & $5-12$ \\
\hline & PE & 28 & $21-38$ & 31 & $27-35$ \\
\hline \multirow{4}{*}{$\begin{array}{c}8 \\
\text { Peito de peru } \\
\text { ligth } \\
\text { marca } 5\end{array}$} & Total & 59 & $48-69$ & 65 & $59-72$ \\
\hline & PE & 28 & $21-36$ & 30 & $25-37$ \\
\hline & EVOH & 7 & $4-10$ & 7 & $4-11$ \\
\hline & PE & 29 & $23-35$ & 29 & $23-35$ \\
\hline \multirow{4}{*}{$\begin{array}{c}9 \\
\text { Presunto } \\
\text { cozido } \\
\text { marca } 5\end{array}$} & Total & 64 & $52-72$ & 70 & $66-75$ \\
\hline & PE & 28 & $22-36$ & 28 & $25-32$ \\
\hline & $\mathrm{EVOH}$ & 11 & $6-17$ & 12 & $10-15$ \\
\hline & PE & 25 & $17-31$ & 29 & $25-35$ \\
\hline \multirow{5}{*}{$\begin{array}{c}10 \\
\text { Presunto } \\
\text { cozido } \\
\text { marca } 4 \\
200 \mathrm{~g}\end{array}$} & Total & 109 & $91-129$ & 180 & $164-197$ \\
\hline & PET & 74 & $57-88$ & 131 & $121-165$ \\
\hline & PVDC & 5 & $3-9$ & 7 & $5-9$ \\
\hline & PA & 5 & $3-6$ & 5 & $3-7$ \\
\hline & EVA & 26 & $21-36$ & 36 & $29-42$ \\
\hline
\end{tabular}

Valores referentes a $80\left(^{(a)}\right.$ e $30\left(^{(b)}\right.$ determinações IV: intervalo de variação met: metalização

*: vide Figura 1 
ao oxigênio (Tabelas 2 e 3 ) não é comprometido por um fechamento deficiente. Tanto nas embalagens de salsicha e de lingüiça como nas de frios fatiados, a termossoldagem da tampa ao fundo é feita por meio de barras aquecidas com perfil plano. Todas as embalagens de lingüiça e salsicha não agregam a conveniência da fácil abertura, ou seja, somente são abertas com o auxílio de um instrumento cortante. Dentre as 10 embalagens de frios fatiados avaliadas, 8 apresentavam fácil abertura, o que revela a tendência de oferecer ao consumidor maior conveniência no momento do consumo de um produto de alto valor agregado, capaz de absorver o incremento de custo que este sistema acarreta.

Nas Tabelas 4 e 5 são apresentadas a distribuição de espessura no fundo, total e por camada de material plástico presente na estrutura, em embalagens termoformadas de salsicha e de frios fatiados, adquiridas no mercado.

Conforme já comentado, o fundo das embalagens de salsicha e lingüiça encontrados no mercado são basicamente compostos por quatro camadas de material polimérico, suficientes para conferir a resistência mecânica e a barreira ao oxigênio exigida pela maioria dos produtos cárneos. Contudo, na amostra "Lingüiça de Frango marca 4" foi detectada a presença de EVOH, material com maior barreira ao oxigênio que a poliamida. Este recurso permite reduzir a espessura total da estrutura e, consequentemente, aumentar sua transparência e flexibilidade, sem perda de barreira e, em alguns casos, até ganho nesta propriedade, dependendo da espessura de material.

A termoformação consiste basicamente no estiramento do material de embalagem. Com isto, tem-se uma redução na espessura do filme plano original, principalmente nos cantos, considerados como pontos críticos. No caso das embalagens de salsicha e lingüiça analisadas (500 g, profundidade de termoformação da ordem de $35 \mathrm{~mm}$ ), a redução na espessura total dos cantos em relação ao topo da lateral, onde a espessura manteve-se praticamente inalterada, foi da ordem de 42 a $65 \%$. Considerando as duas camadas responsáveis pela barreira ao oxigênio na embalagem (PA/PA ou PA/ EVOH), a redução foi da ordem de 44 a $66 \%$.

No mercado de frios fatiados, a exemplo do que ocorre no de salsicha e lingüiça, há o predomínio de embalagens a vácuo termoformadas (profundidade entre 15 e $20 \mathrm{~mm}$ ), neste caso em porções de $100 \mathrm{~g}$ para salames e 200 a $250 \mathrm{~g}$ para presuntos. Estas embalagens, entretanto, são do tipo skin packaging, que se caracterizam por uma conformação do fundo ou tampa ao produto e completa aderência de ambos nas regiões aonde não existe produto. Desta forma, minimiza-se a exsudação e favorece-se a eliminação de oxigênio ao mesmo tempo em que obtém-se uma excelente apresentação do produto.

Nos frios fatiados, a redução de espessura nos cantos da embalagem foi, em geral, maior que no centro. Nos cantos, a redução na espessura total em relação ao filme plano (Tabela 3 ) variou de cerca de 5 a $24 \%$. No centro, a variação foi de até $16 \%$.

Nas amostras 1, 2 e 3 que utilizam a mesma estrutura de fundo, a redução na espessura total das camadas barreira a gases atingiu $62 \%$ nos cantos e $57 \%$ no centro do fundo, em relação ao filme plano, o que certamente acarreta a deterioração do produto acondicionado a partir destas regiões, tanto em termos de descoloração quanto microbiologicamente.

De modo geral, nas amostras de 1 a 6 , a espessura total e das camadas barreira a gases, no centro do fundo e nos cantos, era da mesma ordem de grandeza.

Nas amostras de 7 a 9, a termoformação era bastante irregular, acompanhando o arranjo e o formato das fatias de produto. Desta forma, a redução nas espessuras total (até $12 \%$ ) e da camada barreira a gases (até $42 \%$ ) nos cantos das embalagens com fatias com formato redondo (amostras 7 e 8) foi mais acentuada que naquela com fatia retangular, amostra 9 , com redução de 4,5 e $8 \%$ na espessura total e na camada de EVOH, respectivamente, sempre em relação ao filme plano.

$\mathrm{Na}$ amostra 10, cujas fatias de produto além de uniformes eram colocadas uma sobre a outra, a termoformação do fundo era bastante regular, fazendo a embalagem lembrar uma pequena bandeja. Neste tipo de termoformação, o canto é o ponto crítico da embalagem, o que se torna claro ao observar que a espessura total do canto é cerca de $39 \%$ inferior à do centro e a espessura no canto das camadas de PA e de PVDC, principais responsáveis pela barreira a gases da embalagem, é $18 \%$ inferior à do centro.

Os resultados obtidos para as amostras de mercado confirmam que a termoformação leva à perda de barreira a gases de maneira significativa, devido à redução na espessura, mesmo em bandejas rasas, como a de frios fatiados, o que justifica o uso de $\mathrm{EVOH}$, como verificado na maioria das estruturas de mercado.

\section{Conclusões}

Nas embalagens a vácuo para produtos cárneos analisadas, a barreira a gases está associada, principalmente às resinas de poliamida e EVOH. Os filmes com EVOH em geral apresentaram taxa de permeabilidade ao oxigênio inferior à $20 \mathrm{~cm}^{3} / \mathrm{m}^{2} / \mathrm{dia}$, à úmido, a $23{ }^{\circ} \mathrm{C}$ e $1 \mathrm{~atm}$. Valores superiores foram obtidos com poliamidas. As resinas de EVOH são uma opção para filmes de espessura fina, em que se tem redução de material, sem comprometimento das propriedades de barreira. Filmes revestidos com PVDC têm sido uma opção de material barreira para tampas de embalagens termoformadas. Portanto, a diversidade de barreira ao oxigênio verificada é grande, basta ajustá-la à exigência de cada produto.

Nas embalagens termoformadas, o efeito da luz como catalisador da reação de oxidação, principalmente de pigmentos, tem sido evitado pela pigmentação do filme da tampa, além da impressão.

Os filmes de fundo para bandejas termoformadas parecem ser o material de embalagem que exige maior aprimoramento no mercado brasileiro de embalagens para produtos cárneos. Tratam-se de filmes cuja barreira é dada especialmente pelas poliamidas, que também conferem às estruturas propriedade de termoformação. São filmes de permeabilidade intermediária, muitas vezes utilizados com tampas de alta 
barreira. A permeabilidade das embalagens termoformadas fica ainda mais comprometida pelo estiramento do material especialmente nos cantos da bandeja. O aprimoramento das propriedades de termoformação destas estruturas, para minimizar a redução da espessura nos cantos é imprescindível, ainda mais que a etapa de produção da bandeja é feita pelo usuário da embalagem, que nem sempre domina tecnologias associadas a materiais poliméricos.

\section{Agradecimentos}

Os autores agradecem à Fapesp pelo apoio financeiro.

\section{Referências Bibliográficas}

1. Robertson, G.L. - "Food packaging-principles and practice", Marcel Dekker Inc, New York (1992).

2. Sarantópoulos, C. I. G. L.; Oliveira, L. M.; Anjos, V. D. A.; Alves, R. M. V. \& Ardito, E. F. G. "Embalagem para produtos cárneos", CETEA/ITAL, Campinas (1994).

3. Sarantópoulos, C. I. G. L.; Oliveira, L. M.; Padula, M.; Coltro, L.; Alves, R. M. V. \& Garcia, E. E. C. "Embalagens plásticas flexíveis - principais polímeros e avaliação de propriedades", CETEA/ITAL, Campinas (2002).
4. ASTM F 1306-90 (reapproved 1998) - "Standard test method for slow rate penetration resistance of flexible barrier films and laminates'. ASTM Standards on Disc. Philadelphia, v.15.09, 4p.

5. ASTM F 1927-98 - "Standard test method for determination of oxygen gas transmission rate, permeability and permeance at controlled relative humidity through barrier materials a coulometric sensor". ASTM, 6p. (2001).

6. Oliveira, L. M.; Sarantópoulos, C. I. G. L. \& Cunha, D. G. Composição e propriedades de estruturas plásticas multicamadas para embalagem de produtos cárneos, in: Anais CBECIMAT, 6p., Natal-RN (2002).

7. Fantoni, R.F. Cristalização e nucleação da poliamida 6 filmgrade, in: Anais da $3^{\text {a }}$ Conferência Internacional de Embalagens Flexíveis - TAPPI/CETEA, 22p., Campinas-SP (2003).

8. Goetz, W. Polyamide for flexible packaging film, in: Anais da $3^{\text {a }}$ Conferência Internacional de Embalagens Flexíveis - TAPPI/CETEA, 14p., Campinas-SP (2003).

Enviado: 27/06/05

Reenviado: 08/02/06

Aprovado: 07/03/06 